\title{
Marek Jeziński (red.). 2009. Nowe media i polityka. Internet, demokracja, kampanie wyborcze. Toruń: Wydawnictwo Adam Marszałek, ss. 291
}

W

zrastająca rola nowych mediów we współczesnej polityce, zwłaszcza w okresie kampanii wyborczych, coraz częściej staje się tematem debat i analiz. Książka Nowe media i polityka. Internet, demokracja, kampanie wyborcze pod redakcją Marka Jezińskiego jest jedną z niewielu publikacji kompleksowo ukazujących związki polityki z nowymi mediami. Zawiera ona prezentację najnowszych badań empirycznych odwołujących się do bieżących wydarzeń na scenie politycznej.

Sposób, w jaki Marek Jeziński zebrał i zaprezentował artykuły badaczy, znakomicie wprowadza, a zarazem porządkuje i uzupełnia dotychczasową wiedzę na temat funkcjonowania nowych mediów w obszarze aktywności politycznej społeczeństw w systemach demokratycznych. Dodatkowo wstęp, którym redaktor opatrzył książkę, daje obraz złożoności zjawiska polityki w nowych mediach oraz syntetycznie wskazuje na kierunki podjętych przez autorów badań i poruszane wątki.

Zarówno tytuł publikacji, jak i poszczególnych jej części trafnie sygnalizuje zawartość pracy. Ujęcie problemowe pozwoliło uporządkować artykuły badaczy w dwóch częściach: pierwsza, zatytułowana Demokracja, media, zawiera refleksje odnoszące się do zagadnień nowych mediów w kontekście kształtowania demokracji i społeczeństwa obywatelskiego, w drugiej - Internet w polityce - polityka w Internecie - pojawiają się rozważania na temat funkcjonowania Internetu jako medium służącego aktywności politycznej.

Pierwszą część książki otwiera artykuł Pawła Antkowiaka Wpływ nowoczesnej technologii na procesy demokratyczne, ukazujący znaczenie i konsekwencje osiągnięć techniki w systemie demokratycznym na płaszczyźnie technologicznej i społecznej. Autor na podstawie literatury rozróżnia i analizuje pojęcia teledemokracji, cyberdemokracji i elektronicznej demokratyzacji. W kontekście procesów demokratycznych zastanawia się również nad korzyściami i zagrożeniami wynikającymi z użytkowania Internetu.

Przykładów ograniczenia wolności słowa i manipulacji politycznej w mediach w ustroju demokratycznym dostarcza Dawid Bunikowski. W artykule Media na usługach polityki, snując rozważania filozoficzne, badacz zastanawia się 
nad teoretycznymi możliwościami wpływu polityki na media. Do problematyki wykorzystywania narzędzi nowych mediów przez szeroko rozumianą politykę wprowadza artykułem Nowe media a polityka. Nowe formy komunikowania w obszarze polityki Piotr Ziarek. Autor podjął udaną próbę ukazania kształtowanego przez nowoczesną technologię oblicza społeczeństwa sieciowego, ze szczególnym uwzględnieniem komunikacji politycznej. Z kolei Maurycy Graszewicz (Internet w systemie komunikowania politycznego) opisał zalety wykorzystywania potencjału sieci przez polityków jako kolejnego środka komunikacji z wyborcami, wyszczególniając między innymi niskie koszty przekazu oraz kontrolowaną zawartość nadanego komunikatu. O zjawisku „dziennikarstwa społecznego”, tworzonego przez internautów będących odbiorcami, jak również nadawcami komunikatów, pisze Robert Dziemba. Badacz w artykule Nowe media a koncepcja "piątej władzy" stawia pytania o zawartość definicyjną pojęć zarówno„,czwartej”, jak i „piątej władzy”. Nad konsekwencjami stosowania elektronicznych środków przekazywania informacji w społeczeństwie w odniesieniu do uregulowań prawnych Unii Europejskiej zastanawia się Krzysztof Nowakowski (Relacje społeczne ery postindustrialnej). Kwestią granic wolności słowa oraz istnienia i przestrzegania kodeksów etycznych w cyberprzestrzeni zajmuje się natomiast Jerzy Jastrzębski (Etyka nowych mediów). Autor analizuje zjawisko, skupiając się w dużej mierze na kodeksie etycznym organizacji funkcjonującej online CNET Networks, zatrudniającej dziennikarzy, których zainteresowania są związane z nowymi technologiami.

Wątek mediatyzacji polityki we współczesnym świecie i związanych z tym konsekwencji zarówno dla polityków, jak i dla wyborców podejmują Katarzyna Witkowska (Mediatyzacja polityki, czyli obywatel-widz kontra polityk-aktor sceny politycznej) oraz Agnieszka Kasińska-Metryka (W poszukiwaniu hard newsów. Techniki public relations w komunikacji politycznej). Obie badaczki zastanawiają się nad wpływem przekazów medialnych, zwłaszcza telewizyjnych, na ostateczne decyzje wyborców, dostrzegając przy tym pozytywne efekty mediatyzacji rynku politycznego, w tym między innymi profesjonalizację działań politycznych czy szerszy dostęp społeczeństwa do komunikatów politycznych. O zmieniającym się charakterze komunikacji marketingowej w świetle nowych mediów piszą również Sławomir Gawroński i Rafał Polak w artykule Nowe media jako czynnik ewolucyjnych zmian w komunikacji marketingowej. Autorzy podkreślają elementy charakterystyczne dla cybermarketingu, odróżniając go tym samym od wąsko rozumianego marketingu internetowego. Z kolei Małgorzata Wnorowska w pracy Nowe media w okresie hibernacji politycznej przedstawia możliwości, jakie stwarza sieć w obszarze permanentnej komunikacji polityków ze społeczeństwem, zwłaszcza w okresie braku zainteresowania określonym politykiem przez media tradycyjne. Artykuł został ponadto wzbogacony wykresem i przedrukami omawianych stron internetowych. Porównania cech tradycyjnych mediów masowych i nowych mediów dokonuje również Izabela Borucińska w tekście Znaczenie Internetu w rozwo- 
ju mass mediów mniejszości polskiej w krajach nadbałtyckich. Tym razem badaczka podjęła próbę uchwycenia znaczenia sieci w rozwoju mediów Polaków na Litwie, Łotwie i w Estonii, wskazując jednocześnie, że Internet stanowi obecnie głównie platformę przekazów tradycyjnych.

Przedmiotem zainteresowania Tomasza Kozłowskiego w artykule $W$ błędnym kole rozrywki. Czy oferta telewizyjna może wpływać na kształt społeczeństwa obywatelskiego w Polsce? jest zagadnienie kształtowania polskiego społeczeństwa obywatelskiego w kontekście zawartości oferowanych przez media programów rozrywkowych.

Drugą część publikacji zatytułowaną Internet w polityce - polityka w Internecie, dotyczącą funkcjonowania najpopularniejszego z nowych mediów - Internetu, otwiera praca Jakuba Nowaka Zrób to sam - Web 2.0 jako sfera politycznej aktywności internautów. Autor prezentuje wnioski dotyczące rosnącej aktywności politycznej internautów w wirtualnej przestrzeni. Podejmuje również wątki wykorzystywania przez polityków blogów, a także popularnej witryny YouTube jako narzędzi kontaktu z potencjalnymi wyborcami. Kwestię praktycznego posługiwania się blogami, jako formą autokreacji wizerunku, wzmocnienia popularności i pozyskiwania elektoratu, rozwijają autorzy kolejnych artykułów. Marek Jeziński w artykule Funkcje blogów politycznych wyróżnia najistotniejsze z punktu widzenia zarówno nadawcy, jak i odbiorcy funkcje blogów: autokreacji politycznej, ekspresywno-emotywną oraz estetyczną, a także informacyjną, integracyjno-ekskluzywną, impresywno-agitacyjną i fatyczną. Z kolei Tomasz Gajowniczek w pracy Polskie blogi jako forma dyskursu politycznego - próba analizy zjawiska omawia praktyczne wykorzystanie blogów przez polskich polityków.

Agnieszka Węglińska w artykule Kampania wyborcza w nowych mediach przypomina wykorzystanie blogów w kampaniach wyborczych w USA. Ponadto autorka zwraca uwagę na prawne aspekty stosowania narzędzi oferowanych przez sieć w kampaniach wyborczych w Polsce, we Francji i w Szwajcarii. Sposoby pozyskiwania wyborców za pośrednictwem Internetu na przykładzie działań podejmowanych przez Socjaldemokrację Polską w latach 2004-2007 prezentuje Wojciech Peszyński (Kampanie internetowe Socjaldemokracji Polskiej). Badacz, analizując zawartość stron internetowych wspomnianej partii i jej poszczególnych reprezentantów, zarówno w okresach kampanii ogólnopolskich, jak i samorządowych, dochodzi do wniosku, że sieć ze względu na wciąż ograniczony zasięg ma drugorzędne i uzupełniające znaczenie w komunikacji z wyborcami. Podobną analizę, jednak w odniesieniu do aktywności kandydatów i ugrupowań w kampanii samorządowej w 2006 roku w województwie kujawsko-pomorskim, przeprowadza Aleksandra Seklecka w artykule Internet w kampanii samorzq̨dowej 2006 na przykładzie województwa kujawsko-pomorskiego). Badaczka zauważa rosnące zainteresowanie podmiotów politycznych działalnością w Internecie zarówno na poziomie lokalnym, jak i regionalnym. Nowe możliwości komunikacji politycznej, 
jakie stwarza Internet, oraz praktyczne ich wykorzystanie na szczeblu gminnym omawia Maria Nowina Konopka w pracy Politycy lokalni a nowe typy komunikacji politycznej w Internecie. O karnawalizacji polityki i kampanii wyborczych w sieci pisze Krzysztof Gajdka (Nie tylko w krzywym zwierciadle. Samorządowcy w portalach JoeMonster.org i YouTube.com). Ponadto treść artykułu uzupełniają adekwatne ilustracje zaczerpnięte ze stron wspomnianych portali.

Dyskusja na temat wprowadzonego w Polsce stanu wojennego stała się przyczynkiem do opracowania Kamili Kamińskiej o tytule Stan wojenny w polskim Internecie. Analizując zawartość witryn instytucji państwowych oraz osób prywatnych, a także internetowe wydania dzienników, badaczka prezentuje skalę zainteresowania wspomnianą tematyką.

Reasumując, należy podkreślić niewątpliwą zaletę recenzowanej publikacji, jaką jest ukazanie szerokiego spektrum problematyki dotyczącej związków między systemem demokratycznym, polityką i nowymi mediami. Zawartość merytoryczna i kompozycja zebranych wypowiedzi uświadamiają czytelnikowi złożoność podejmowanych kwestii, a także dostarczają podstawowych informacji i - co ważne - zachęcają do refleksji (zwłaszcza w aspekcie skuteczności działań marketingowych podejmowanych w sieci). Przydatność tego rodzaju pozycji w poznawaniu mechanizmów marketingu politycznego wydaje się bezsporna.

Małgorzata Adamik (Uniwersytet Marii Curie-Skłodowskiej w Lublinie) 